\title{
An Analysis of the Correlation between Green Supply Chain Transformation and Enterprise Financial Performance
}

\author{
Zhiqin Wei \\ The doctoral student of Wuhan University of Technology, Wuhan, China
}

Keywords: Green supply chain; Financial performance; Technological innovation.

\begin{abstract}
Green building, which is a trend of the development of architectural industry, is encouraged by China, however, domestic green building has developed slowly during the recent ten years. It is because the relativity between the transformation of Environmentally Conscious Supply Chain and enterprise financial performance is uncertain. The thesis constructs the model of green construction supply chain and financial performance. The effect the environmental protection-oriented transformation of green supply chain has on enterprise financial performance is examined by the case analysis of residential construction enterprises. It turns out that with the driving force of technological innovation, it shows positive correlation between the transformation of enterprise environmentally conscious supply chain and enterprise financial performance. This has a constructive guidance significance for accelerating transition of construction enterprises in order to adapt market requirement, raise the standard of financial performance, strengthen the awareness of environmental protection, promote social profit and promote industrialization of green constructions.
\end{abstract}

\section{Introduction}

Construction supply chain is the key point of developing industrialization of national constructions. For promoting the greenness development of construction supply chain, the 13th Five Year Plan of building energy efficiency and green architecture development mentioned that by the time of 2020, the energy efficiency level of urban newly-built constructions will be increased by 20 percent contrasted with 2015. When Evaluation standard for green building (ESGB) in 2006 4th, and The Implementation Suggestions About Accelerating the Proportion of the Development of Green Constructions jointly released by the Ministry of Finance and the department of housing construction in 2012 come out, national green constructions cover the area of 165 billion square meters in 2015 , which occupy the proportion of 3.9 percent of the 4208 Floor Space of Building Completed of 4208 billion square meters. It turns out that there is still a greet distance between policy orientation and enterprise implementation. The main cause is that enterprises are unwilling to devote for technological innovation because of the lack of orientation of environmental protection. And tracing the source, the enterprises worry that the transformation of green supply chain will have great influence of enterprise financial performance.

However, what impact does green supply chain of architecture have on enterprise financial performance? There are different conclusion on present researches. Positive and negative correlation are always uncompromising with each other. Our thesis constructs the model of green construction supply chain and financial performance in order to examine the positive and negative correlation between the transformation of green supply chain of architecture and enterprise financial performance by practical case analysis of the enterprise, besides, it provides decision support for the transformation of green supply chain of construction enterprise.

\section{Research Hypothesis and Model}

\subsection{Build hypothesis}

With the great support on green construction industry and the development of technological 
innovation taken by our government. Every link of corporation in construction supply chain tend to invest in developing the innovative research of environmental technology and green technology. What technique innovation can do is that making investment for technological innovation and product research at first, then bringing the improvement of the management efficiency and the lower of management cost, and optimizing the performance of corporate financial in the end.

The technological innovation in the green supply chain of construction business mainly refers to a method which adopts new technique or new materials to shorten working hours, reduce pollution or emission and save energy., and hence the technological innovation in construction business can effectively reduce the waste of materials, time, and the cost of promoting the condition of environment, and cut the prime cost of consumption. Furthermore, the reduction of prime cost can availably enhance the profitability and competitiveness of the company, which have a positive impact on the enterprise financial performance. Based on the analysis above, two assumptions are made as follows:

Assumption 1: the technological innovation has positive correlation with the environmental protection of the company.

Assumption 2: the technological innovation has positive impact on the enterprise financial performance

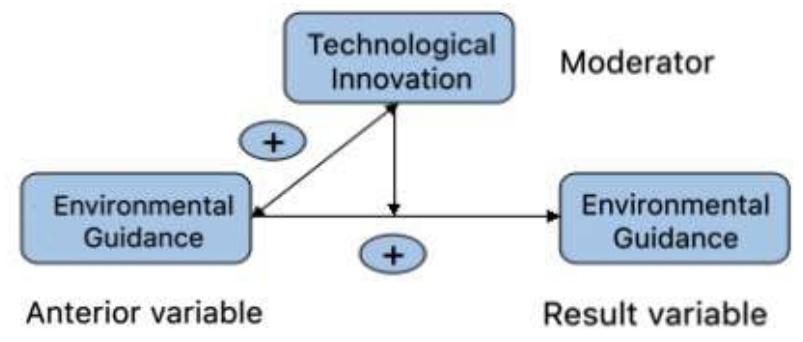

Figure 1 The Relationship between Environmental Protection and Financial Performance in the Green Supply Chain of Construction Industry

\subsection{Research model}

Construction of green supply chain includes the green procurement, green transportation, green inventory and logistics optimization model. etc. Among them, green purchasing includes buying the energy saving material which has small pollution and emission to the environment, or cooperating with green materials suppliers ; Green transport (logistics) includes choosing the mode of transportation of low energy consumption, or the optimization of mode of transport and route scheme; Green construction includes the link of the construction of water pollution, waste pollution and solid pollution and so on, which is effective to reduce the pollution to the environment.

Construction enterprise environmental orientation is the basic principles of green building construction industry supply chain. This thesis directs the construction enterprises in the supply chain environmental indicators which are divided into enterprise culture of environmental protection, environmental information disclosure and environmental governance investment. Setting up enterprise culture is to promote environmental protection concept to both internal and external to the construction enterprise or put strategy of environmental protection into the reform of the management; Environmental information disclosure is mainly to disclose environmental matters of external reports in listed companies and accept social supervision behaviors; Environmental governance investment mainly includes the investment of the green purchasing, technology updating and pollution treatment.

Technological innovation is an only way to the reform of modern building industrialization, and technology innovation has brought the management efficiency and lower management costs. Building environmental technology innovation refers to achieve energy conservation, emissions reduction and reduce the production period by adopting new technology, new process and new materials. Construction technology innovation, therefore, can effectively reduce the production of the waste materials, working hours, environmental control, and reduce the cost.

According to the related literature analysis, environmental orientation to the enterprise financial 
performance comes from the enterprise itself and the influence of environment, such as the factors of technology innovation. This paper constructs the theoretical model of "the orientation of environmental protection-----technology innovation, ----enterprise financial performance". The diagram is shown in the figure below:

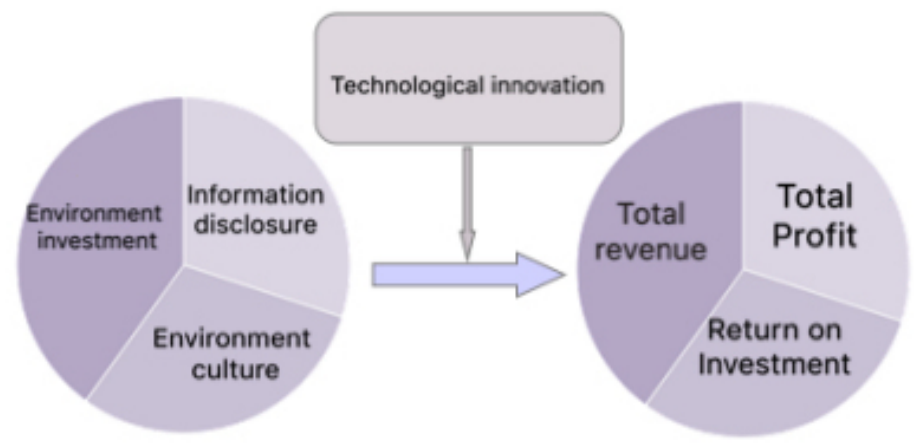

Figure 2 Construction Industry Green Supply Chain Environmental Impact on Financial Performance Model

\section{Case Analysis}

Our thesis takes Vanke Enterprise Co., Ltd. as an example to conduct a practical analysis of the model, and then test the hypothesis.

Business background. Wan Ke was founded in May, 1984. In1988, Wan ke is concerned into the field of residence, which is becoming the core business in the company. On the way to civilization of green architecture. Wan Ke built the conference of searching building in 1999.Up to now, it become the system of the standard of residence and the system of technology of green building. From June 1st, 2014, all the program of Wan ke acted on the level of one-star to build. Every year it formulated the standard of the area of three stars level's building as well as the standard of the area of residence, and then examines every branch each year. From 2013, wan ke fully implements the strategy of green building. All the program of new residence acted on the local program together with the standard of design of national green building to build, and be approved by the design of level of the green building. In 2014, the research institute of Qing hua and the studying center of Havard were built. they were focus on the residence of green building. On March 15th of this year, qinghua hengda and havard built the study base of green building.

Vanke enterprises environmental protection factors include: corporate environmental culture, environmental information disclosure and environmental protection investment. Since 2013, the company has implemented green supply chain transformation in the project and products, mainly has transformed the green supply chain from the three aspects: the application of prefabricated components, assembly wall and interior and exterior wall plastering, and continuously has improved the green building area.

Table 1 Vanke Green Building Schedule (2013-2016)

\begin{tabular}{|l|l|l|l|l|}
\hline & 2016 & 2015 & 2014 & 2013 \\
\hline $\begin{array}{l}\text { Prefabricated } \\
\text { components }\end{array}$ & & & & \\
$\begin{array}{l}\text { Assembled interior } \\
\text { wall }\end{array}$ & $43.5 \%$ & $39 \%$ & $27 \%$ & $8.3 \%$ \\
$\begin{array}{l}\text { Inside and outside the } \\
\text { wall without plastering } \\
\text { application ratio }\end{array}$ & $100 \%$ & $100 \%$ & $100 \%$ & $38.8 \%$ \\
\hline $\begin{array}{l}\text { Green Building } \\
\begin{array}{l}\text { Completed Area } \\
\text { (10,000 square meters) }\end{array}\end{array}$ & 2,834 & $100 \%$ & $87 \%$ & $29.1 \%$ \\
\hline Growth rate & $101.5 \%$ & $59.8 \%$ & 880.1 & 172.7 \\
\hline
\end{tabular}

At the same time, Vanke launched a series of "green-oriented" measures for enterprises to bring a 
huge reputation of goodwill assets and brand assets:

"Vanke" began to enter the green building in 2011, its "Four Seasons Flower City", "City Garden", "Golden Home" and other green brands achieves the industry's first position;

"Scene green garden house" developed by the company is green building industry's first patented product and the first invention patent; company property services pass through the first batch of ISO9002 quality system certification;

"Million guest" founded by the company is the green building industry's first customer relationship organization;

Research and application of Vanke green factory technology make important progress, a number of projects (represented by green residential industrial base located in Dongguan) was awarded as "national housing industry base." by the Ministry of Construction.

The green supply chain transformation brought about the growth of corporate financial performance: Vanke operated income of 240.4 billion yuan in 2016, with year-on-year growth of 133 percent contrasted by 2012 with average annual increase of 33.25\% ,operating profit in 2016 is 39 billion yuan, with year-on-year growth of $85.7 \%$ contrasted by 2012, with average annual increase of 17.14\%; net profit is 20.9 billion yuan in 2016, with year-on-year growth of $67.2 \%$ with average annual increase of $13.44 \%$.

Table 2 Vanke Financial Performance Data Summary (2013-2016)

\begin{tabular}{|l|l|l|l|l|l|}
\hline & 2016 & 2015 & 2014 & 2013 & 2012 \\
\hline $\begin{array}{l}\text { Operating income (100 million } \\
\text { yuan) }\end{array}$ & 2404 & 1955 & 1463 & 1354 & 1031 \\
\hline Growth rate & $22.98 \%$ & $33.58 \%$ & $8.10 \%$ & $31.32 \%$ & - \\
\hline Operating profit (billion) & 390 & 331 & 249 & 242 & 210 \\
\hline Growth rate & $17.82 \%$ & $32.60 \%$ & $2.96 \%$ & $15.23 \%$ & - \\
\hline Net profit (billion) & 209 & 176 & 155 & 151 & 125 \\
\hline Growth rate & $18.81 \%$ & $13.09 \%$ & $3.03 \%$ & $20.8 \%$ & - \\
\hline
\end{tabular}

The Precast Technology is a new type of environmental friendly technology in China's modern construction industry. Through the use of prefabricated components, the enterprise has saved more than $50 \%$ costs in the areas of material, energy, water and labor efficiently and achieved a true state of green production, green construction and green residential. And thanks to the environmental protection investment, it has also won the support of national fiscal policy. From 2013 to 2016, as a result of the environmental protection investment, the enterprise has made a great profit in two important aspects including cost and tax revenue in financial performance. In terms of cost, it has reduced the risk of damage and the relationship between external stakeholders; the cost of raw materials, energy and services; capital costs and labor costs. With regard to income tax, it has enjoyed an exemption in environmental protection material value added tax, business income tax and other tax incentives. Both financial performance have effectively improved the profitability of this enterprise.

\section{Conclusion and Discussion}

The above analysis can be seen that in the construction of modern architecture industrialization system, it makes higher requirements to the green supply chain in all aspects of enterprises' environmental guidance. Enterprises must establish the correct thinking of environmental friendly, strengthen the green business and adhere to the concept of sustainable development at first. Secondly, from the perspective of stakeholders, enterprises should pay attention to the development of the overall environmental friendly performance of stakeholders in the supply chain. Enterprises in all aspects of the supply chain accept the rules of environmental friendly or actively carry out environmental friendly measures to enhance their own green management efficiency. Only in the above situation, the construction supply chain can achieve the objectives of green construction 
industry supply chain, and then achieve the sustainable development goals in economic development, social development and environmental protection.

In this essay, there are some shortcomings in the research study of the impact of environmental guidance in green supply chain to corporate financial performance. Firstly, the limitations of the argument. Online second-hand data and related information have limitations in the verification hypothesis and also lack of more effective evidence. Secondly, the performance of different types of construction enterprises have differences in the specific characteristics of environmental guidance. This difference may change the impact of the precondition on the outcome factors.

\section{References}

[1] Zhou Yongzhan, Sheng Yanmei, Zhao Meiping. Performance Evaluation of Green Supply Chain under Low Carbon Perspective [J]. Journal of Liaoning Technical University (Social Science Edition), 2015,03: 236-239 (In Chinese)

[2] Hu Xinting. On the environmental impact of enterprise investment in financial efficiency factors and enhance the countermeasures [J]. Journal of Hunan University of Finance and Economics, 2012,06: 109-112 (In Chinese)

[3] Hu Xinting. On the environmental impact of enterprise investment in financial efficiency factors and enhance the countermeasures [J]. Journal of Hunan University of Finance and Economics, 2012,06: 109-112 (In Chinese)

[4] Yan Ruizeng, Feng Yunwen. Regional industrial environment on the impact of business performance research based on the "Eleventh Five-Year" period of regional data empirical analysis [J]. Entrepreneurs heaven and earth (the second half), 2014,05: 3-7 (In Chinese)

[5] Pan Fei, Wang Liang. The relationship of enterprise environmental investment and economic performance research [J]. New Accounting, 2015,04: 6-11 (In Chinese) 